\title{
The complex Robertsonian system of Dichroplus pratensis (Melanoplinae, Acrididae). II. Effects of the fusion polymorphisms
on chiasma frequency and distribution
}

Claudio J. Bidau*†
Laboratorio de Genética, Departmento de Ciencias Biológicas, Facultad de Ciencias Exactas y Naturales, Universidad de Buenos Aires, Ciudad Universitaria, 1428 Buenos Aires, República Argentina.

The effects of a complex series of Robertsonian polymorphisms on chiasma frequency and distribution were analysed in natural populations of the grasshopper Dichroplus pratensis which has a standard karyotype of $2 n=19$ (XOठ) telocentrics. Populations are usually polymorphic for one to three of seven distinct fusions between the six large $\left(\mathrm{L}_{1}-\mathrm{L}_{6}\right)$ autosomes. The study revealed that:

1. Standard males have an essentially proximal-distal pattern of chiasma distribution. Interstitial chiasmata are less frequent.

2. Fused males have significantly fewer total and proximal chiasmata than standards from the same population but show an increase in interstitial and distal chiasmata.

3. The former is due to the fact that centric fusions, either homozygous or heterozygous, produce a decrease in total chiasma frequency of the involved chromosomes and a redistribution of chiasmata resulting in a sharp reduction of proximal chiasmata and an increase in interstitial and distal ones. In this respect, there are no significant differences between fusion trivalents and corresponding fusion bivalents. The same chromosomes in the basic homozygous state, have a typical standard chiasma pattern.

4. The effects of each fusion are intrachromosomal and although the same chiasma repatterning occurs in all seven fusions, total reduction in chiasma frequency depends on the telocentrics involved since a highly significant positive correlation exists between telocentric length and chiasma frequency. Since all chromosome arms tend to have a minimum of one chiasma, the effects of a fusion are more marked in longer autosomes.

5. Comparisons of populations that differ for number and frequency of fusions, showed a highly significant negative correlation between mean number of different fusions per male (per population) $(\bar{F})$ and total chiasma frequency per cell $\left(X_{t a}\right)$. The same type of correlation exists between $\bar{F}$ and proximal $X_{t a}$ and $\bar{F}$ and between-cell variance of total $X_{t a}$ frequency, while a positive correlation was found between $\bar{F}$ and mean interstitial chiasmata.

6. According to 5 , intrachromosomal recombination within populations decreases as number and frequency of fusions increase. This effect is added to the instant reduction of interchromosomal recombination produced by the combination of two linkage groups into one.

These results suggest that redistribution of chiasma patterns is due to a direct effect of the rearrangements. Furthermore, the changes in chiasma patterns are discussed in relation to the maintenance of the polymorphisms since trivalents require the elimination of proximal and interstitial chiasmata for balanced orientation and segregation. This was corroborated by the finding of a population in which three fusions were fixed. Here, proximal and interstitial chiasmata in the fused chromosomes are significantly more frequent than expected. Finally, the modifications of recombination potential are discussed relative to the possible adaptive role of these widespread polymorphisms and to a model of chromosomal evolution for the species.

\footnotetext{
* Member of the Carrera del Investigador Científico y Tecnológico, CONICET.

† Present address: Departamento de Genética, Facultad de Ciencias Exactas, Químicas y Naturales, Universidad Nacional de Misiones, Félix de Azara 174, 3300 Posadas, Misiones, República Argentina.
}

\section{INTRODUCTION}

The effects of chromosomal rearrangements on chiasma frequency and localisation have been extensively studied and reviewed in animals and 
plants. Instances of B chromosomes, interchanges, Robertsonian translocations, inversions and supernumerary heterochromatin affecting chiasmata and recombination, have been reported. Intra- and interchromosomal effects have been demonstrated (Hewitt, 1979; Parker et al., 1982; Sperlich and Pfriem, 1986; White, 1973).

A distinction must be made however, between the effects of spontaneous and polymorphic rearrangements since in many cases, the survival and establishment of a stable polymorphic condition or conversely, its transience and the consequent elimination or fixation of a given karyomorph may depend on a reorganisation of the chiasma patterns in the involved chromosomes. Such is the case of centric fusions. In a small number of cases of spontaneous fusions studied in grasshoppers, no modifications of chiasma patterns were apparent in the resultant trivalents (Colombo, 1987; Kayano and Nakamura, 1960; López-Fernández et al., 1984; Southern, 1967; Teoh and Yong, 1983). However, in the few cases of fusion polymorphisms studied in depth, the rearranged chromosomes showed modifications in chiasma frequency and localisation which allow stable convergent orientation and normal segregation of trivalents in heterozygotes (Bidau, 1984; Bidau and Hasson, 1984; Bidau and Mirol, 1988; Colombo, 1987, 1988; Hewitt and Schroeter, 1968). In some cases however, chromosomes may be preadapted to exist in a polymorphic state if they have low frequencies and distal localisation of chiasmata as in the Coleopteran Chilocorus (Smith and Virkki, 1978). However, this is not always so since trivalents of hybrids between $C$. tricyclus and $C$. hexacyclus show high frequencies of non-conver- gent orientation despite strong distal localisation of chiasmata (Smith, 1966).

The modifications mentioned above have an additional secondary effect which is the reduction of intrachromosomal (as well as interchromosomal) recombination and this may be of evolutionary significance since it could allow the maintenance of adaptive supergenes.

The grasshopper Dichroplus pratensis Bruner offers a unique opportunity to study these effects. This South American melanopline is widespread in Argentina, Uruguay and Southern Brazil (Liebermann, 1963) and comprises several chromosomal races that differ with respect to number and frequency of at least seven different fusions that involve six pairs of large autosomes. With a single exception, all populations already sampled are polymorphic for one to three fusions. Karyotypes, geographic distribution of polymorphisms and meiotic behaviour of heterozygotes have already been described (Bidau, 1984, 1988; Bidau and Mirol, 1988).

In this paper the relationship of the fusion polymorphisms of $D$. pratensis to changes in chiasma frequency and localisation are studied in several Argentine populations.

\section{MATERIAL AND METHODS}

This study is based on 297 males of $D$. pratensis collected by the author and collaborators at the localities shown in table 1. A much larger number of males has been cytologically studied, especially at Sierra de la Ventana, being the subject of forthcoming papers; however, some data of these are

Table 1 Origin of the populations whose chiasma characteristics are described in table VII. All populations are polymorphic for the involved fusions except $\mathrm{C}$ in which three fusions have become fixed. Populations $\mathrm{K}$ and $\mathrm{SV}$ belong to hybrid zones which result from the overlapping of chromosome races that differ for fusions with monobrachial homologies

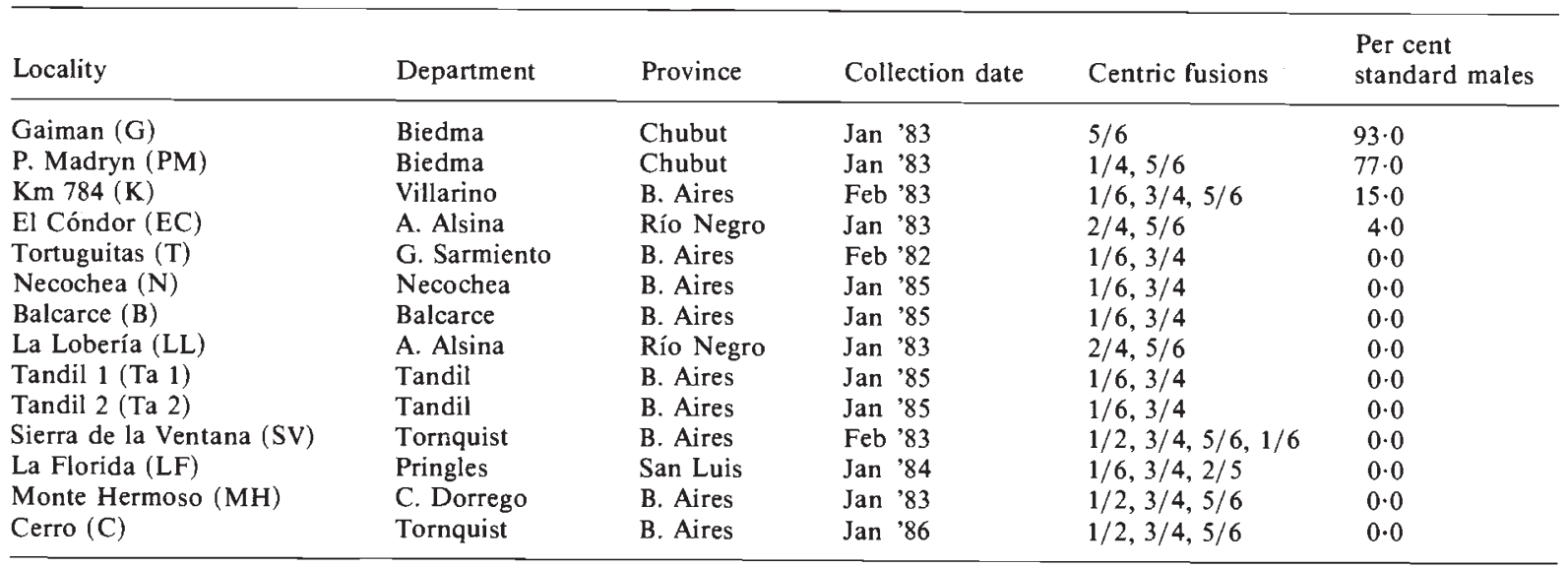


incorported in this paper. All males were processed in the field. Testes were fixed in 3:1 alcohol-acetic and squashed in lacto-propionic orcein.

Chiasmata were scored at MI since orientation of bivalents and trivalents at this stage allows easy identification of chiasma position. Ten cells were scored per male and chiasmata classified as proximal (P), interstitial (I) and distal (D) according to their location in the first (proximal), second or third portion of the chromosome or chromosome arm when the latter are divided in equal parts.

\section{RESULTS}

\section{The karyotype and fusion polymorphisms}

\section{of $\mathrm{D}$. pratensis}

The Robertsonian system of the species has already been described (Bidau, 1984, 1986, 1988). The karyotype comprises in its standard form, six pairs of large telocentric autosomes $\left(\mathrm{L}_{1}-\mathrm{L}_{6}\right)$, three small telocentrics $\left(S_{7}-S_{9}\right)$ of which $S_{7}$ is the megameric bivalent and $\mathrm{S}_{8}$ carries the single standard NOR, and one $(\delta)$ or two ( $\$$ ) medium-sized telocentric $\mathrm{X}$ chromosomes. $\mathrm{L}_{1}-\mathrm{L}_{6}$ chromosomes can be unambiguously recognised by distinctive length. Only $\mathrm{L}_{6}$ can be identified by heterochromatin content since it usually has a C-positive heterochromatic block at its telomeric end. The six L autosomes are involved in fusions and seven different fusions have been identified $(1 / 2 ; 1 / 4$; $1 / 6 ; 2 / 4 ; 2 / 5 ; 3 / 4 ; 5 / 6)$. Some populations are polymorphic for a single fusion, some for two and some for three although not necessarily the same ones since the same telocentric is involved in different fusions. Hybrid zones between chromosomal races have been identified and within them, popultions may be polymorphic for four fusions with monobrachial homologies (Bidau, 1988).

\section{Chiasma frequency and localisation in standard and fused males}

Until the present, no completely standard (st) population has been found in the sampled areas. Indeed, st individuals are very rare (Bidau, 1988) due to the numbers and frequencies of the fusions present. Only two populations showed high frequencies of $s t$ males: Puerto Madryn (PM) and Gaiman (G) (table 1), both from Chubut and about $80 \mathrm{~km}$ apart. The first one is polymorphic for fusions $1 / 4$ and 5/6. In Gaiman, a single 5/6 heterozygote was found among 14 males sampled. The standard individuals from these populations were assumed to display the typical chiasma pat- terns of non-fused individuals of all populations studied although variations between populations probably do occur. Nevertheless, st's from PM and $\mathrm{G}$ were very similar regarding chiasma frequency and localisation (table 2) (see also Bidau, 1984).

Fig. 1 shows chiasma patterns of several distinct fusion karyomorphs. The $\mathrm{S}$ bivalents never form more than one chiasma that may be P, I or D although the latter predominante (fig. $1(\mathrm{a})-(\mathrm{h})$ ). Telocentric L bivalents never form more than two chiasmata (fig. 1(a)-(c), (f), (h)). Monochiasmate $\mathrm{L}$ bivalents usually have a $\mathrm{P}$ or a $\mathrm{D}$ chiasma (fig. 1(a)-(c), (f), (h)), seldom an I one (fig. 1(b)). Bichiasmate telocentric $\mathrm{L}$ bivalents are very frequently P/D (fig. 1(a), (b), (h)), sometimes I/ D (fig. 1(f)) and only rarely P/I. A summary of chiasma frequencies and distribution in telocentric $\mathrm{L}$ bivalents of standard males is given in table 2 . Chiasma conditions are radically altered in metacentric fused chromosomes as discussed below (fig. $1(\mathrm{c})-(\mathrm{h}))$. There is a highly significant correlation between chiasma frequency per bivalent and chromosome length (fig. 2; table 3 ) within the L group. The correlation does not hold for the $\mathrm{S}$ bivalents since there must always be a chiasma present for proper segregation.

Frequencies of total (T), P, I and D chiasmata in 47 st males from PM are shown in fig. 3(a)-(d). These are not significantly different from those of the $s t$ 's from G. That is, standards have a mainly $\mathrm{P} / \mathrm{D}$ distribution, I chiasmata being rare (Bidau, 1984). In PM, 15 males carrying fusions (all of them heterozygotes) wre found: nine had the $1 / 4$ fusion, five the $5 / 6$ fusion and the remaining one was a double $1 / 4,5 / 6$ heterozygote. These males, when considered jointly showed significantly fewer total chiasmata than the $s t$ males from the same population (fig. 3(a)). This was mainly due to a significant decrease in $\mathrm{P}$ chiasmata (fig. 3(b)). D and I chiasmata were, on the contrary, higher in heterozygotes (fig. 3(c)-(d)). Chiasma frequencies and distribution of individual 1-1.4-4 and 5-5.6-6 trivalents are summarised in table 4.

In order to test for possible interchromosomal effects, mean cell chiasma frequencies $(\bar{X})$ excluding chromosomes 1 and 4 in one case, and 5 and 6 in the other, were calculated in ten randomly chosen non-fused males. The same was done with nine $1 / 4$ and five $5 / 6$ heterozygotes. The chiasma frequencies thus calculated were not significantly different in both cases (non fused, $\bar{X}=7.86$ vs. $1 / 4, \bar{X}=7 \cdot 71 ; F_{1,189}=1 \cdot 56 ; P>0.05 ;$ non-fused, $\bar{X}=8 \cdot 30$ vs. $\left.5 / 6, \bar{X}=8 \cdot 56 ; F_{1,149}=1 \cdot 92 ; P>0.05\right)$. These results suggest that the effect of the fusions on shiasma frequency are exerted solely upon the 


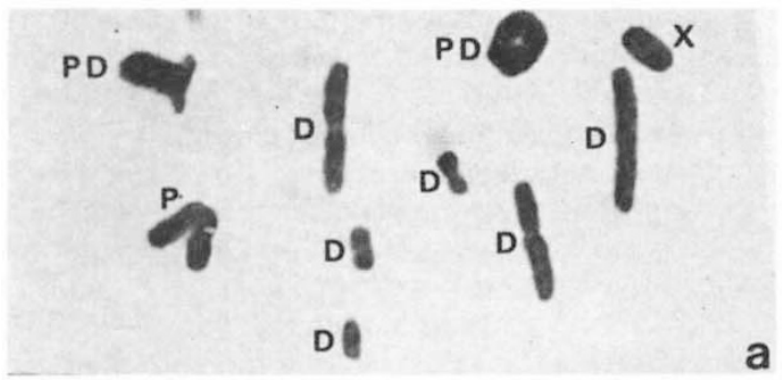$$
\text { c }
$$

$$
\text { (1) }
$$

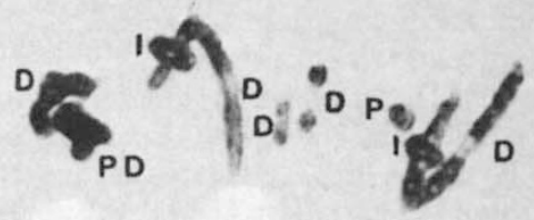

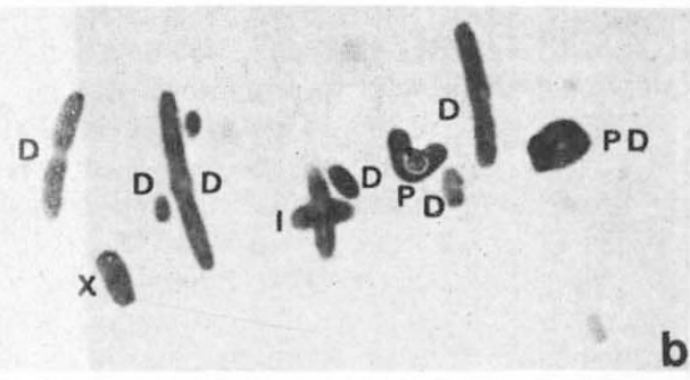

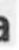

$6 x$$$
\mathrm{D}
$$$$
\text { P2. }
$$$$
\text { D }
$$

e
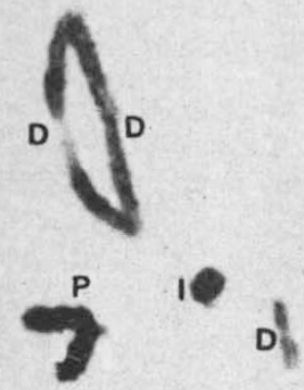
Table 2 A summary of chiasma frequencies and distribution in the L bivalents of standard $(2 n=19)$ males of Dichroplus pratensis. Data of each $L$ bivalent (L1-L6) are given for the $G$ (upper row) and PM (lower row) populations. $X_{i}, X_{p}, X_{i}$ and $X_{d}$ are mean numbers of total, proximal, interstitial and distal chiasmata per bivalent, respectively. Percentages are given in parentheses. The right part of the table represents the distribution of bivalents with different localisation of 1 and 2 chiasmata

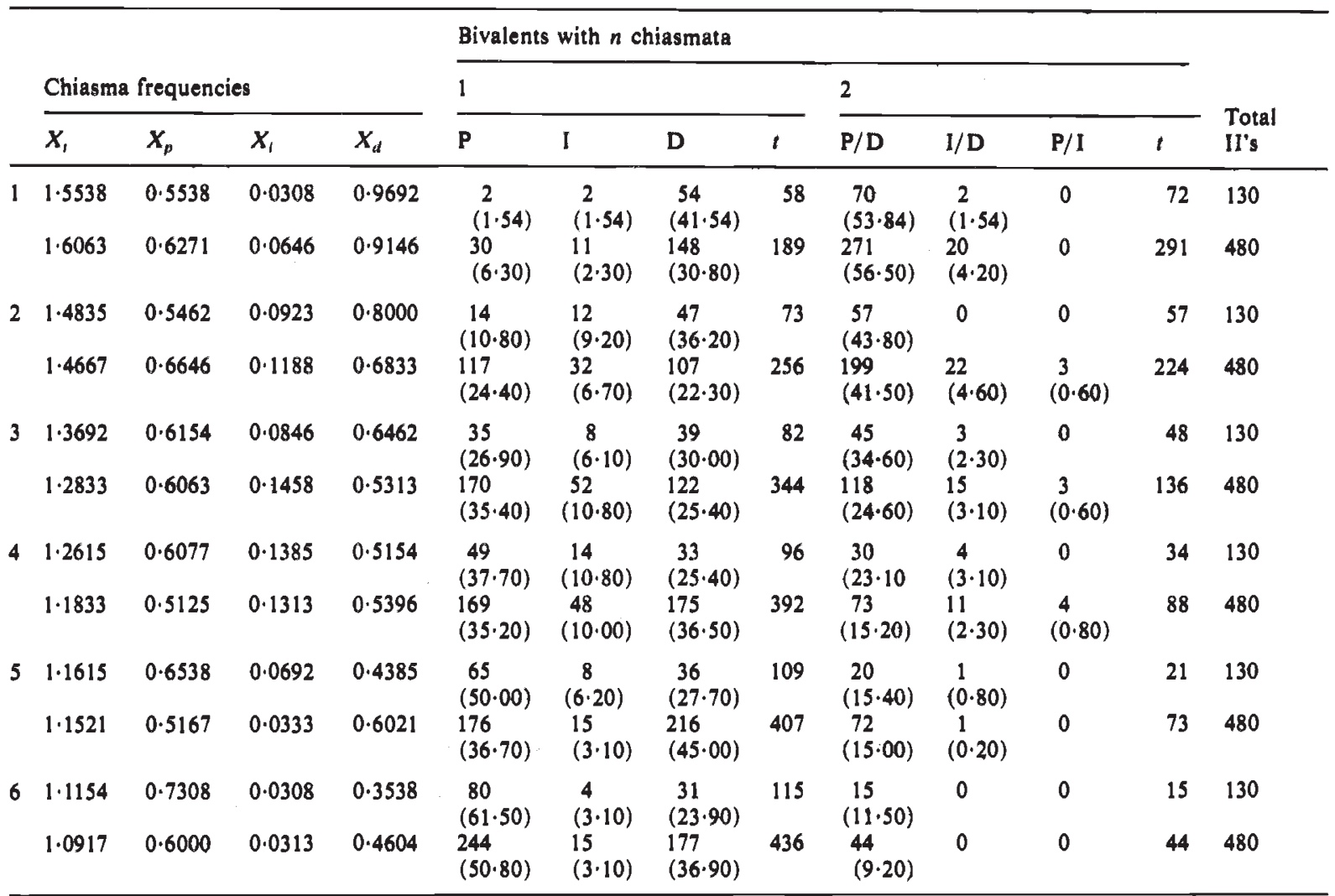

involved chromosomes. The same type of comparison was made for $P, I$ and $D$ chiasmata and again, differences were not statistically significant. The other fusions studied produce similar effects on chiasma frequency and distribution (see for example, table 6).

Furthermore, these results indicate that the two fusions affect chiasma frequency differently. This is expected since in st males, chromosomes 1 and 4 have on average more chiasmata than 5 and 6 (table 3; fig. 2). This is corroborated by the following: (a) while mean cell chiasma frequency of $s t$ 's is 10.75 , that of $1 / 4$ heterozygotes is $9.83\left(F_{1.559}=\right.$ $42.30 ; P<0.01)$ and that for $5 / 6$ heterozygotes, $10.52\left(F_{1,519}=1.46 ; P>0.05\right)$; (b) when unfused chromosomes 1 and 4 or 5 and 6 are compared with their fusion counterparts as in fig. 4(a), (b) it is obvious that in both cases, chiasma frequency is reduced in the fused chromosomes though the effect is less marked in the $5 / 6$ fusion as expected; (c) when $1 / 4$ and $5 / 6$ heterozygotes were compared with respect to total chiasma frequency, the difference was highly significant $\left(F_{1.139}=18.26\right.$; $P<0.01)$ but the reduction in proximal chiasmata is similar $\left(F_{1,139}=0.31 ; P>0.05\right)$.

It was considered relevant to compare fusion heterozygotes and homozygotes regarding chiasma frequency. Since males differing karyotypically only for the fusion in question are difficult to find in sufficiently large numbers owing to the nature of the polymorphisms, comparisons were made solely between the trivalent and the corresponding

Figure 1 Chiasma distribution at MI in Dichroplus pratensis males. (a), (b). Two cells from a standard male ( $2 n=19$ ). (c) Hom $1 / 6$, Het $3 / 4(2 n=16)$. (d) Triple $2 / 5,3 / 4,1 / 6 \mathrm{Het}$; the $1 / 6$ trivalent is linearly oriented; note distal localisation of chiasmata $(2 n=16)$. (e) Het $1 / 6$, Hom $2 / 5,3 / 4(2 n=14)$. (f) Het $1 / 6$, Hom $3 / 4(2 n=16)$. (g) Double $1 / 6,3 / 4 \mathrm{Het}, 2 / 5 \mathrm{Hom}(2 n=15)$; note exceptional proximal chiasma in bivalent $2 / 5$ (left). Het $1 / 6$, Hom $3 / 4$. References: P (proximal), I (interstitial), D (distal). $\mathrm{Bar}=10 \mu \mathrm{m}$. 


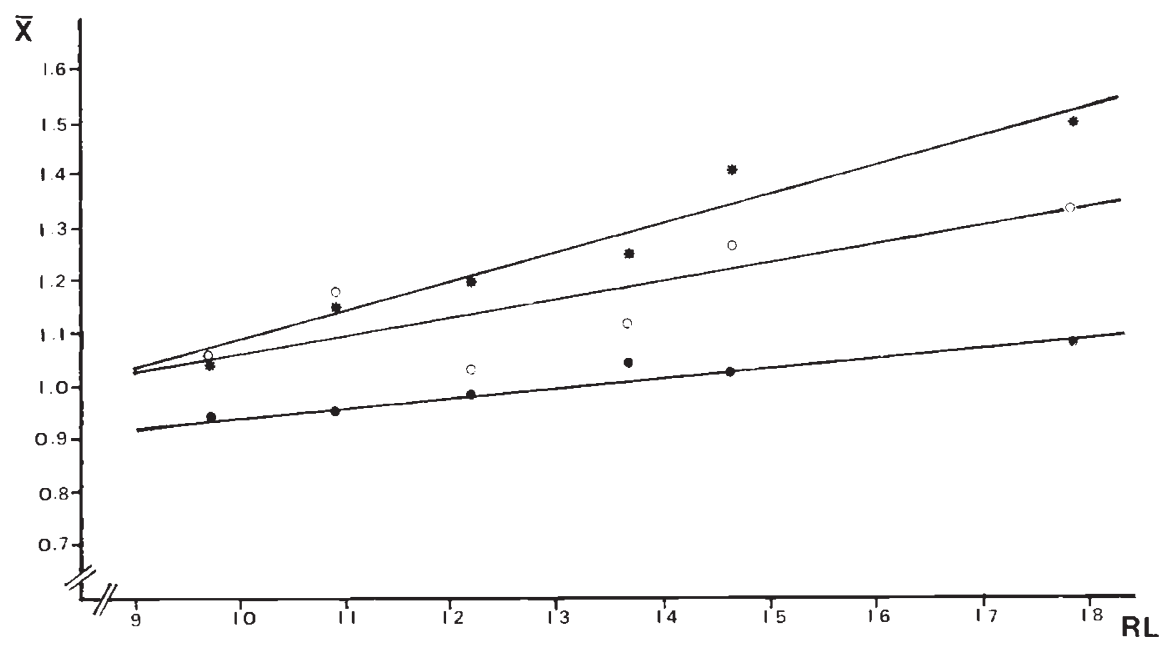

Figure 2 Relationship between relative L chromosome length (RL) and chiasma frequency per chromosome or chromosome arm in ten standard males $(*)$, ten randomly chosen males from a polymorphic population for fusions $1 / 2,3 / 4$ and $5 / 6(O)$ and ten males from a population with the same fusions fixed (O). Regression equations and their significance are given in table 3 .

fusion bivalent. The fact that no interchromosomal effects have been detected (see above) was considered. The comparisons were made using individuals from the SV, LF and EC populations. As can be seen in tables 5 and 6 , no significant differences between Hets. and Homs. are apparent (interstitial chiasmata are however, more frequent in fusion bivalents than in trivalents).

These results suggest that the recombination capacity of a given population (hence its potential ability for the liberation of genetic variability) depends on the quality, number and frequency of the fusions present.

\section{Inter-population comparisons}

It is worth noting that interchromosomal recombination is instantly reduced as a consequence of a centric fusion. Two independent linkage groups are combined into one thus reducing the number of elements that are randomly transmitted to the gametes. Chiasma frequency reduction is added to this effect producing a generalised decrease in recombination.

To test this prediction, the mean number of different fusions per individual $(\bar{F})$ was calculated for each population (table 7). Mean cell total, proximal, interstitial and distal chiasma frequency and inter cell variance of total chiasma frequency, were plotted against $\bar{F}$. The results of the regression analyses (figs. 5 and 6) show that T, P and I chiasma frequency and inter-cell variance depend significantly upon $\bar{F}$.

A further confirmation of this effect was obtained when populations SV, PM and C were compared for chiasma frequency on each $\mathrm{L}$ chromosome or chromosome arm. Ten males from each sample were considered: ten $s t$ 's from PM, ten triple homozygotes $(1 / 2,3 / 4,5 / 6)$ from $C$ and

Table 3 Chiasma frequency per L chromosome or chromosome arm based on ten randomly chosen standard males (a) from PM population, ten from a polymorphic population (b) (SV population polymorphic for $1 / 2,3 / 4$ and $5 / 6$ fusions) and ten from a monomorphic population (c) (C population; fusions $1 / 2,3 / 4$ and $5 / 6$ fixed)

\begin{tabular}{|c|c|c|c|c|c|c|c|}
\hline & & \multicolumn{6}{|c|}{$\mathrm{L}$ chromosome or chromosome arm } \\
\hline & & 1 & 2 & 3 & 4 & 5 & 6 \\
\hline Mean relative length ( $R L)$ & & $17 \cdot 85$ & $14 \cdot 67$ & $13 \cdot 68$ & $12 \cdot 20$ & $10 \cdot 93$ & $9 \cdot 72$ \\
\hline Mean chiasma frequency per & (a) & $1.49 \pm 0.05$ & $1.40 \pm 0.05$ & $1 \cdot 25 \pm 0 \cdot 04$ & $1 \cdot 20 \pm 0.04$ & $1 \cdot 15 \pm 0.04$ & $1.05 \pm 0.02$ \\
\hline L chromosome or chromosome & (b) & $1 \cdot 33 \pm 0.05$ & $1 \cdot 26 \pm 0.04$ & $1 \cdot 12 \pm 0 \cdot 03$ & $1.03 \pm 0.02$ & $1 \cdot 18 \pm 0.04$ & $1.06 \pm 0.02$ \\
\hline $\operatorname{arm}(\overline{\mathrm{X}} \pm \mathrm{SE})$ & (c) & $1 \cdot 08 \pm 0.03$ & $1 \cdot 02 \pm 0.02$ & $1.04 \pm 0.02$ & $0.98 \pm 0.03$ & $0.95 \pm 0.03$ & $0.94 \pm 0.03$ \\
\hline
\end{tabular}

(a) RL vs. $\bar{X} . Y=0.54+0.055 X ; F(1,4)=93 \cdot 70 ; P<0.01$.

(b) RL vs. $\mathrm{X} . \mathrm{Y}=0.74 \pm 0.032 \mathrm{X} ; \mathrm{F}(1,4)=6.96 ; \mathrm{P}<0.01$.

(c) RL vs. $\bar{X}$. $Y=0.76+0.018 X ; F(1,4)=78.86 ; P<0.01$. 
a

b
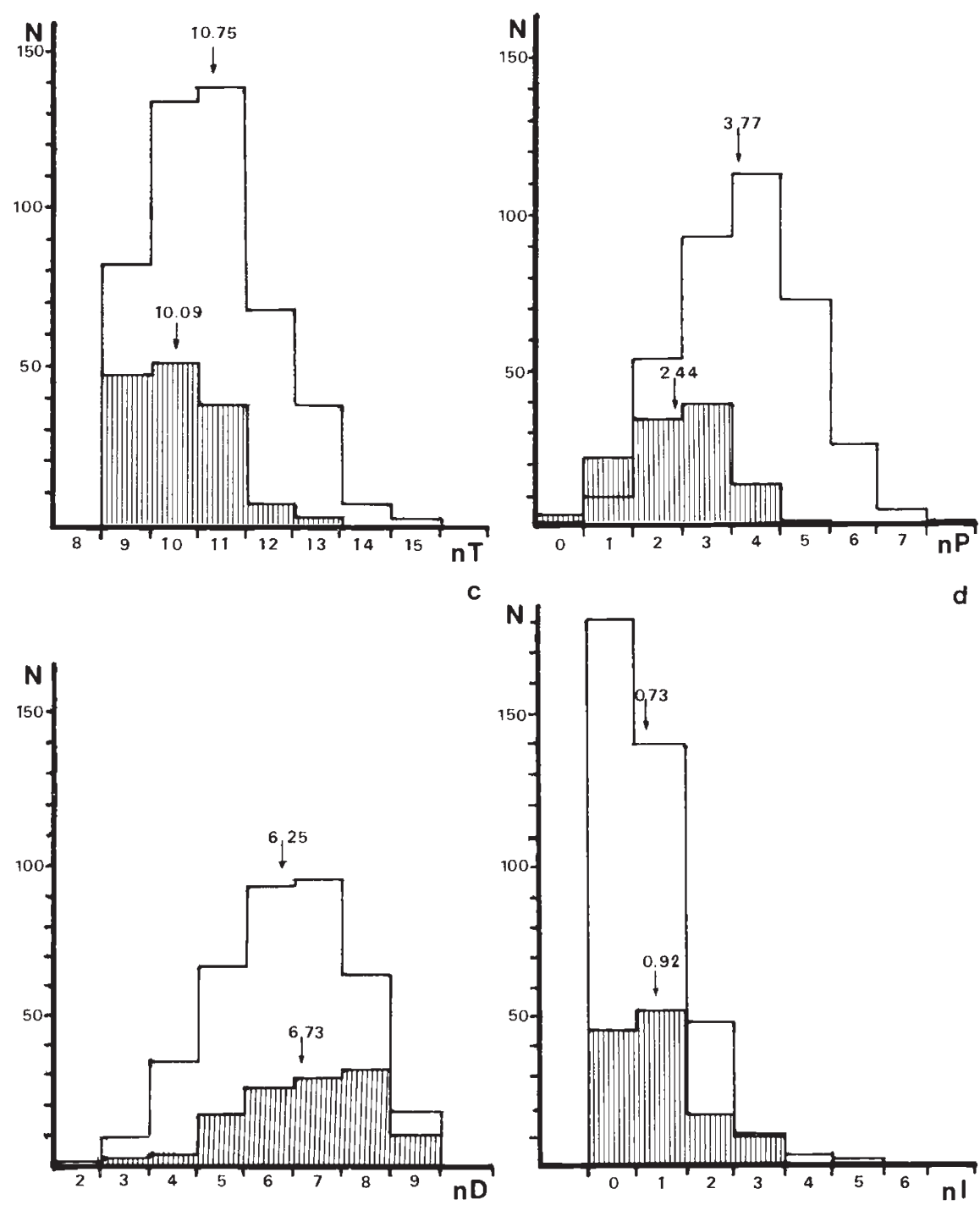

Figure 3 Distribution of the number of (a) total (T), (b) proximal (P), (c) distal (D) and (d) interstitial (I) chiasmata in standard (open histograms) and fused (shaded histograms) males of the PM population. Means are indicated. Results of the respective analyses of variance are: (a) $F_{1,168}=32.5 ; P<0.001$; (b) $F_{1,168}=134.6 ; P<0.001$; (c) $F_{1,168}=12 \cdot 3 ; P<0.001 ;$ (d) $F_{1,168}=5 \cdot 4$; $P<0.001$.

ten randomly chosen males (including individuals with 1,2 and 3 fusions) from the highly polymorphic SV population. From fig. 2 it can be seen that the relationship between chromosome length and chiasma frequency varies according to the number of fusions present (table 3 ).

\section{DISCUSSION}

The presence of chromosomal polymorphisms in natural populations is frequently associated with profound effects on intra- and/or interchromosomal recombination. Examples can be found in different organisms and include inversions in Drosophila and some grasshoppers (Confalonieri, 1988; Confalonieri and Colombo, 1989; Goñi et al., 1985; Hewitt, 1979; Sperlich and Pfriem, 1986; Weissman, 1976; White and Morley, 1955), supernumerary segments in many Orthoptera (Hewitt, 1979; John, 1983; Riva et al., 1984), B chromosomes (Jones and Rees, 1982), etc. The mechanism by which recombination is modified depends on the rearrangement involved and may imply vari- 

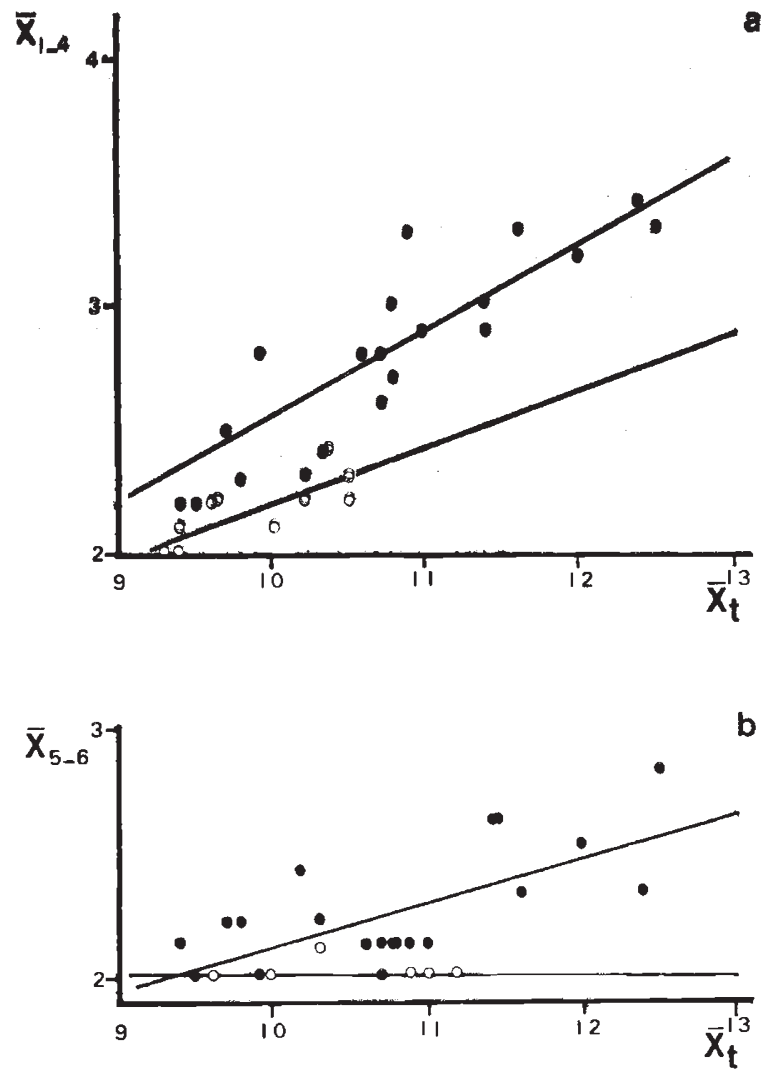

Figure 4 Relationship between total chiasma frequency $(\bar{X} t)$ and chiasma frequency of the unfused $(O)$ or fused $(O)$ $1+4$ (a) and $5+6$ (b) chromosomes in males from PM. (a) Unfused: $Y=0.8125+0.3362 X ; r=0.87, t=7.48, \mathrm{df}=18$, $P(0.001 ;$ Fused: $Y=0.2391+0.1954 X ; r=0.74, t=3.10$, $\mathrm{df}=8,0.02<0.01$. (b) Unfused: $Y=0.4498+0.1661 X$; $r=0.66, \mathrm{df}=18,0.01<P<0.001 ;$ Fused : $Y=2.1195-$ $0.0098 ; r=-0.15, t=0.30, \mathrm{df}=4,0.90<P<0.70$.

ation in cross-over frequency, localisation or both. It is worth noting that the changes in recombination imposed by polymorphic rearrangements do not necessarily reflect the original modifications produced by the spontaneous chromosome mutations which gave rise to them (Colombo, 1987). Furthermore, the overall effect is certainly the result of a complex interaction between the mechanical and genetic properties and restrictions of the rearrangements themselves and the genetic factors that control crossing-over, as well as natural selection. It is a fact that a chromosomal rearrangement never behaves exactly the same in different individuals (Bidau and Mirol, 1988).

For the establishment of a chromosomal polymorphism it is indispensable that heterozygotes do not have their fertility severely reduced by the meiotic misbehaviour of the involved chromo-
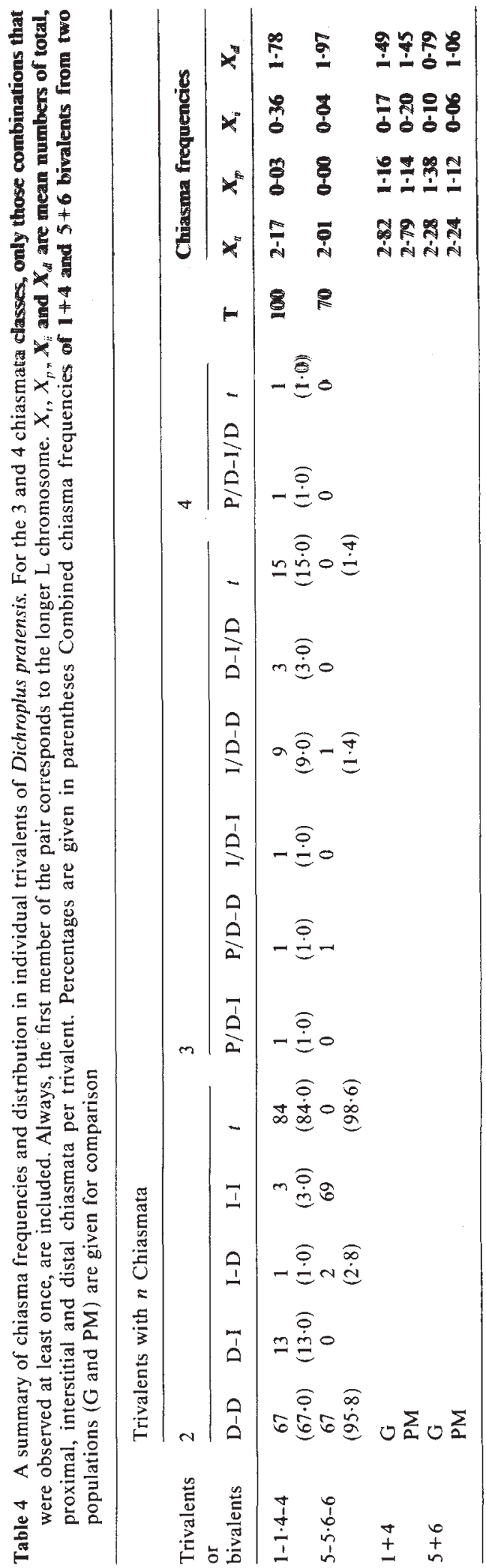
Table 5 A summary of chiasma frequency and distribution of different fusions of Dichroplus pratensis in the homozygous, heterozygous and standard states. Only those chiasma configurations that were observed at least once, are included. The configurations for the fusions in the standard form result from the combination of the chiasma patterns of both telocentric bjvalents from the same cell; the same applies for standard chiasma frequencies

\begin{tabular}{|c|c|c|c|c|c|c|c|c|c|c|c|c|c|}
\hline & & & 1 & & & 2 & & & & & & & \\
\hline Fusio & & & D-O & P-O & I-O & D & D-I & D-P & & I-P & $D P$ & P/D-O & I/D-O \\
\hline $1 / 2$ & SV & Hom & - & - & - & $70 \cdot 0$ & 17.5 & - & 2.5 & - & - & - & - \\
\hline & & Het & - & - & - & $54 \cdot 0$ & $21 \cdot 0$ & - & $4 \cdot 0$ & - & - & - & - \\
\hline & & St & - & - & - & $4 \cdot 4$ & - & 14.4 & - & $1 \cdot 1$ & $1 \cdot 1$ & - & - \\
\hline $3 / 4$ & SV & Hom & 0.7 & - & 0.3 & $72 \cdot 4$ & $10 \cdot 3$ & 0.3 & $3 \cdot 1$ & - & - & - & 0.3 \\
\hline & & Het & - & - & - & $58 \cdot 0$ & $27 \cdot 3$ & 0.7 & 1.3 & - & - & - & - \\
\hline $3 / 4$ & LF & Hom & - & - & - & 86.7 & 8.3 & - & - & - & 0.8 & - & - \\
\hline & & Het & - & - & - & $76 \cdot 2$ & $20 \cdot 0$ & $1 \cdot 2$ & - & - & - & - & 1.2 \\
\hline & & St & - & - & - & $3 n: 4$ & & $30 \cdot 0$ & - & - & $10 \cdot 0$ & - & - \\
\hline $5 / 6$ & EC & Hom & $5 \cdot 0$ & - & $1 \cdot 0$ & $71 \cdot 0$ & $17 \cdot 0$ & $2 \cdot 0$ & $3 \cdot 0$ & - & $1 \cdot 0$ & - & - \\
\hline & & Het & - & - & - & 74.6 & $20 \cdot 0$ & $3 \cdot 6$ & 1.8 & - & - & - & - \\
\hline & & St & - & - & - & $2 \cdot 5$ & $5 \cdot 0$ & $12 \cdot 5$ & $5 \cdot 0$ & $7 \cdot 5$ & $30 \cdot 0$ & - & - \\
\hline & & Hom & - & - & - & 57.5 & $20 \cdot 0$ & 2.5 & - & - & - & - & - \\
\hline $5 / 6$ & SV & Het & - & - & - & $68 \cdot 2$ & $20 \cdot 9$ & 0.9 & $2 \cdot 7$ & $1 \cdot 8$ & - & - & - \\
\hline & & St & - & - & - & $15 \cdot 8$ & 1.7 & $27 \cdot 5$ & $0 \cdot 8$ & $4 \cdot 2$ & $4 \cdot 2$ & - & - \\
\hline $1 / 6$ & LF & Hom & $7 \cdot 1$ & 1.4 & $2 \cdot 9$ & $32 \cdot 9$ & $32 \cdot 9$ & 1.4 & $4 \cdot 3$ & 1.4 & - & 1.4 & - \\
\hline & & Het & $2 \cdot 3$ & - & - & $68 \cdot 5$ & 14.5 & 0.8 & $4 \cdot 6$ & - & - & - & - \\
\hline & & St & - & - & - & - & - & $20 \cdot 0$ & - & - & $20 \cdot 0$ & - & $\ldots$ \\
\hline $1 / 6$ & SV & Hom & - & - & - & 93.4 & $3 \cdot 3$ & - & - & - & - & - & $\cdots$ \\
\hline & & Het & - & - & - & $70 \cdot 0$ & $18 \cdot 2$ & 0.9 & 0.9 & - & - & - & $\cdots$ \\
\hline & & St & - & - & - & $22 \cdot 5$ & 2.5 & $25 \cdot 0$ & - & - & $2 \cdot 5$ & - & - \\
\hline $2 / 5$ & LF & Hom & $1 \cdot 0$ & - & - & $60 \cdot 0$ & $23 \cdot 0$ & - & $2 \cdot 0$ & $3 \cdot 0$ & - & $1 \cdot 0$ & -- \\
\hline & & Het & - & - & - & $80 \cdot 0$ & $11 \cdot 4$ & - & - & - & - & - & - \\
\hline & & St & - & - & - & $2 \cdot 5$ & $2 \cdot 5$ & $5 \cdot 0$ & - & 5.0 & $40 \cdot 0$ & - & $\ldots$ \\
\hline $2 / 4$ & $\mathrm{EC}$ & Hom & 6.0 & $2 \cdot 0$ & - & $60 \cdot 0$ & $28 \cdot 0$ & - & $4 \cdot 0$ & -. & - & - & $\ldots$ \\
\hline & & Het & - & - & - & $50 \cdot 0$ & $41 \cdot()$ & - & $7 \cdot 0$ & $\ldots$ & - & - & - \\
\hline & & St & - & - & - & -- & $2 \cdot 9$ & 11.4 & $2 \cdot 9$ & 8.6 & $22 \cdot 9$ & - & $\cdots$ \\
\hline & & & 3 & & & & & & & & & & \\
\hline Fusio & & & $\mathrm{P} / \mathrm{D}-\mathrm{P}$ & $\mathrm{P} / \mathrm{D}-\mathrm{I}$ & P/D-P & $1 / D-P$ & $1 / D-1$ & I/D-D & $P / I-P$ & & & & \\
\hline & & & $\mathrm{P}-\mathrm{P} / \mathrm{D}$ & $1-P / D$ & D-P/D & $\mathrm{P}-\mathrm{I} / \mathrm{D}$ & $I-I / D$ & $D-I / D$ & $\mathrm{P}-\mathrm{P} / \mathrm{I}$ & & & & \\
\hline $1 / 2$ & SV & Hom & - & - & $2 \cdot 5$ & - & - & $5 \cdot 0$ & $\ldots$ & & & & \\
\hline & & Het & - & - & $3 \cdot 0$ & -- & $1 \cdot 0$ & $17 \cdot 0$ & - & & & & \\
\hline & & St & $10 \cdot 0$ & $4 \cdot 4$ & $33 \cdot 3$ & $4 \cdot 4$ & - & $1 \cdot 1$ & $1 \cdot 1$ & & & & \\
\hline $3 / 4$ & SV & Hom & 0.3 & 0.3 & 0.3 & - & $0 \cdot 3$ & $11 \cdot 0$ & - & & & & \\
\hline & & Het & $1 \cdot 3$ & - & - & - & - & $11 \cdot 3$ & - & & & & \\
\hline $3 / 4$ & LF & Hom & - & - & - & - & $0 \cdot 8$ & $2 \cdot 5$ & - & & & & \\
\hline & & Het & - & - & - & - & - & $1 \cdot 2$ & - & & & & \\
\hline & & St & - & $10 \cdot 0$ & $20 \cdot 0$ & - & - & -- & - & & & & \\
\hline $5 / 6$ & $\mathrm{EC}$ & Hom & - & - & - & - & - & - & -- & & & & \\
\hline & & Het & - & - & - & - & - & - & - & & & & \\
\hline & & $\mathrm{St}$ & $22 \cdot 5$ & $7 \cdot 5$ & $7 \cdot 5$ & - & -- & -- & -- & & & & \\
\hline $5 / 6$ & SV & Hom & - & - & $2 \cdot 5$ & - & $2 \cdot 5$ & 12.5 & - & & & & \\
\hline & & Het & - & - & - & - & 1.8 & $3 \cdot 6$ & - & & & & \\
\hline & & St & $15 \cdot 0$ & $5 \cdot 8$ & $15 \cdot 0$ & 0.8 & - & $\begin{array}{r}3 \cdot 3 \\
11 \cdot 4\end{array}$ & I & & & & \\
\hline $1 / 6$ & $\mathrm{EC}$ & $\begin{array}{l}\text { Hom } \\
\text { Het }\end{array}$ & - & - & $\overline{0}_{0.8}$ & $\overline{-}$ & $\begin{array}{l}2 \cdot 9 \\
2.3\end{array}$ & $\begin{array}{r}11.4 \\
6.2\end{array}$ & - & & & & \\
\hline & & St & $10 \cdot 0$ & - & $30 \cdot 0$ & - & -- & -- & - & & & & \\
\hline $1 / 6$ & SV & Hom & - & - & - & - & -.. & $3 \cdot 3$ & - & & & & \\
\hline & & $\mathrm{Het}$ & - & - & - & - & 0.9 & $8 \cdot 2$ & -. & & & & \\
\hline & & St & $22 \cdot 5$ & - & $7 \cdot 5$ & $5 \cdot 0$ & $2 \cdot 5$ & $2 \cdot 5$ & $5 \cdot()$ & & & & \\
\hline $2 / 5$ & LF & Hom & - & $1 \cdot 0$ & $1 \cdot 0$ & - & $1 \cdot 0$ & $6 \cdot 0$ & $1 \cdot 0$ & & & & \\
\hline & & Het & - & - & 一 & - & - & $8 \cdot 6$ & - & & & & \\
\hline & & St & $25 \cdot 0$ & $2 \cdot 5$ & $7 \cdot 5$ & - & -- & - & $\cdots$ & & & & \\
\hline $2 / 4$ & $\mathrm{EC}$ & Hom & - & - & - & - & - & - & - & & & & \\
\hline & & $\mathrm{Het}$ & - & $2 \cdot 0$ & - & - & - & - & - & & & & \\
\hline & & St & 31.4 & $7 \cdot 1$ & $8 \cdot 6$ & - & - & - & - & & & & \\
\hline
\end{tabular}


Table 5 continued

4

\begin{tabular}{|c|c|c|c|c|c|c|c|c|c|c|c|}
\hline \multicolumn{3}{|c|}{ Fusion } & \multirow{2}{*}{$\begin{array}{l}\text { I/D-I/D } \\
2 \cdot 5\end{array}$} & \multicolumn{2}{|l|}{ P/D-I/D } & $\begin{array}{l}\mathrm{P} / \mathrm{I}-\mathrm{P} / \mathrm{D} \\
\mathrm{P} / \mathrm{D}-\mathrm{P} / \mathrm{I}\end{array}$ & \multirow{2}{*}{$\mathrm{N}$} & \multirow{2}{*}{$\frac{X t}{2 \cdot 13}$} & \multirow{2}{*}{$\frac{X p}{0.03}$} & \multirow{2}{*}{$\frac{X i}{0.33}$} & \multirow{2}{*}{$\begin{array}{l}\mathrm{Xd} \\
1.77\end{array}$} \\
\hline $1 / 2$ & SV & Hom & & - & - & - & & & & & \\
\hline & & Het & - & - & - & - & 100 & $2 \cdot 21$ & 0.03 & 0.48 & 1.70 \\
\hline & & $\mathrm{St}$ & - & $7 \cdot 8$ & $14 \cdot 4$ & $2 \cdot 2$ & 90 & 3.03 & 1.23 & 0.22 & 1.58 \\
\hline \multirow[t]{2}{*}{$3 / 4$} & SV & Hom & - & - & - & - & 290 & $2 \cdot 12$ & 0.02 & 0.29 & 1.81 \\
\hline & & Het & - & - & - & - & 150 & $2 \cdot 13$ & 0.02 & 0.41 & 1.70 \\
\hline \multirow[t]{3}{*}{$3 / 4$} & LF & Hom & - & - & - & - & 120 & 2.03 & 0.02 & 0.13 & 1.88 \\
\hline & & Het & - & - & - & - & 80 & 2.01 & 0.01 & 0.23 & 1.77 \\
\hline & & St & - & - & - & - & 10 & $2 \cdot 30$ & 0.80 & $0 \cdot 10$ & 1.40 \\
\hline \multirow[t]{3}{*}{$5 / 6$} & EC & Hom & - & - & - & - & 100 & 1.94 & 0.04 & 0.24 & 1.66 \\
\hline & & Het & - & - & - & - & 110 & 2.00 & 0.04 & 0.24 & 1.72 \\
\hline & & St & - & - & - & - & 40 & $2 \cdot 38$ & $1 \cdot 40$ & 0.38 & 0.60 \\
\hline \multirow[t]{3}{*}{$5 / 6$} & SV & Hom & 2.5 & - & - & - & 40 & $2 \cdot 23$ & 0.05 & 0.43 & 1.75 \\
\hline & & Het & - & - & - & - & 110 & 2.05 & 0.03 & 0.35 & 1.67 \\
\hline & & St & - & 0.8 & $7 \cdot 5$ & - & 120 & 2.53 & 1.02 & $0 \cdot 18$ & 1.33 \\
\hline \multirow[t]{3}{*}{$1 / 6$} & LF & Hom & - & - & - & - & 70 & $2 \cdot 03$ & 0.06 & 0.63 & $1 \cdot 34$ \\
\hline & & Het & - & - & - & - & 130 & 2.07 & 0.02 & 0.35 & 1.70 \\
\hline & & St & - & $10 \cdot 0$ & $10 \cdot 0$ & - & 10 & $2 \cdot 80$ & 1.40 & $0 \cdot 10$ & $1 \cdot 30$ \\
\hline \multirow[t]{3}{*}{$1 / 6$} & SV & Hom & - & - & - & - & 30 & 2.03 & 0.00 & 0.07 & 1.96 \\
\hline & & Het & - & 0.9 & - & - & 110 & $2 \cdot 11$ & 0.02 & 0.31 & 1.79 \\
\hline & & St & - & - & 2.5 & - & 40 & $2 \cdot 50$ & 1.03 & 0.20 & 1.27 \\
\hline \multirow[t]{3}{*}{$2 / 5$} & LF & Hom & - & - & - & - & 100 & 2.09 & 0.07 & 0.35 & 1.67 \\
\hline & & Het & - & - & - & - & 70 & $2 \cdot 09$ & 0.00 & 0.20 & 1.89 \\
\hline & & St & - & 2.5 & 7.5 & - & 40 & 2.55 & 1.68 & $0 \cdot 13$ & 0.74 \\
\hline \multirow[t]{3}{*}{$2 / 4$} & $\mathrm{EC}$ & Hom & - & - & - & - & 50 & 1.92 & 0.02 & 0.36 & 1.54 \\
\hline & & Het & - & - & - & - & 100 & 2.02 & 0.02 & 0.57 & 1.43 \\
\hline & & St & - & - & $4 \cdot 3$ & - & 70 & 2.56 & 1.53 & 0.24 & 0.79 \\
\hline
\end{tabular}

somes or else, that the loss in fertility is sufficiently compensated by some selective advantage that the heterozygote might possess.

In the case of fusions, one condition that ensures proper orientation and segregation of trivalents is the absence of proximal chiasmata which, when present, frequently determine linear orientation. For the maintenance of a fusion polymorphism it is then necessary that proximal chiasmata are eliminated either through a direct effect

Table 6 Comparison between chiasma frequencies of different $\mathrm{L}$ chromosome combinations in the heterozygous (Het) and homozygous (Hom) states

\begin{tabular}{|c|c|c|c|c|c|}
\hline Fusion & $\begin{array}{l}\bar{X} \\
\text { Het }\end{array}$ & $\begin{array}{l}\bar{X} \\
\text { Hom }\end{array}$ & $F$ & $d_{f}$ & $P$ \\
\hline $1 / 2$ & $\begin{array}{l}n=100 \\
2 \cdot 25 \pm 0.04\end{array}$ & $\begin{array}{l}n=40 \\
2 \cdot 10 \pm 0 \cdot 05\end{array}$ & 3.97 & 1,138 & $0.05-0.01$ \\
\hline $3 / 4$ & $\begin{array}{l}n=100 \\
2 \cdot 12 \pm 0 \cdot 03\end{array}$ & $\begin{array}{l}n=100 \\
2 \cdot 19 \pm 0 \cdot 04\end{array}$ & 0.87 & 1,198 & $>0.05$ \\
\hline $5 / 6$ & $\begin{array}{l}n=100 \\
2.08 \pm 0.03\end{array}$ & $\begin{array}{l}n=50 \\
2 \cdot 18 \pm 0 \cdot 07\end{array}$ & $2 \cdot 95$ & 1,148 & $>0.05$ \\
\hline $1 / 6$ & $\begin{array}{l}n=110 \\
2 \cdot 10 \pm 0 \cdot 03\end{array}$ & $\begin{array}{l}n=30 \\
2 \cdot 10 \pm 0 \cdot 06\end{array}$ & 0.00 & 1,138 & $>0.05$ \\
\hline
\end{tabular}

of the rearrangement or by selection against proximal chiasma formation (unless preadaption in the form of strong distal localisation in telo/acrocentrics occurs).

When considering the multiple fusion polymorphisms of $D$. pratensis two points are then worthy of discussion; first, the initial establishment of the polymorphisms and second, the possible adaptive significance of the fusions themselves and the modifications on recombination. Both points are, however, intimtely related.

In the three thoroughly studied cases of fusion polymorphism in Acrididae, those of Oedaleonotus enigma (Hewitt and Schroeter, 1968), Leptysma argentina (Bidau and Hasson, 1984; Colombo, 1987, 1988) and D. pratensis (Bidau, 1984, 1986, 1988; Bidau and Mirol, 1988; Tosto et al., 1987; this paper), a marked reduction in proximal chiasmata accompanying a general redistribution of chiasmata in the involved chromosomes of heterozygotes was observed. In all three cases, trivalents show fairly regular orientation and segregation. Indeed, in $D$. pratensis non-convergently oriented trivalents have on average more proximal 
Table 7 Chiasma characteristics of 14 natural populations of $D$. pratensis (for references see table 1)

\begin{tabular}{|c|c|c|c|c|c|c|c|}
\hline Population & $N$ & $\bar{F}$ & $\bar{X}_{t}$ & $\bar{X}_{p}$ & $\bar{X}_{i}$ & $\bar{X}_{d}$ & $S_{t}^{2}$ \\
\hline$G$ & 14 & $0.07 \pm 0.07$ & $10 \cdot 76 \pm 0.11$ & $3 \cdot 57 \pm 0 \cdot 13$ & $0.77 \pm 0.07$ & $6 \cdot 47 \pm 0 \cdot 11$ & 1.674 \\
\hline$P M$ & 62 & $0 \cdot 26 \pm 0 \cdot 06$ & $10 \cdot 59 \pm 0 \cdot 05$ & $3.45 \pm 0.06$ & $0.77 \pm 0.03$ & $6.37 \pm 0.06$ & 1.555 \\
\hline$E C$ & 24 & $1 \cdot 54 \pm 0 \cdot 12$ & $9.92 \pm 0.05$ & $3.42 \pm 0.09$ & $1.09 \pm 0.06$ & $5 \cdot 41 \pm 0 \cdot 10$ & 0.706 \\
\hline$T$ & 13 & $1 \cdot 57 \pm 0 \cdot 14$ & $9.55 \pm 0.06$ & $2 \cdot 01 \pm 0 \cdot 12$ & $0.94 \pm 0.08$ & $6 \cdot 61 \pm 0 \cdot 14$ & 0.529 \\
\hline$N$ & 5 & $1 \cdot 80 \pm 0 \cdot 20$ & $9 \cdot 54 \pm 0 \cdot 10$ & $2 \cdot 20 \pm 0 \cdot 15$ & $1 \cdot 06 \pm 0.13$ & $6 \cdot 28 \pm 0 \cdot 20$ & 0.539 \\
\hline$T a 2$ & 15 & $1.87 \pm 0.09$ & $9.50 \pm 0.07$ & $2 \cdot 01 \pm 0 \cdot 10$ & $1 \cdot 52 \pm 0 \cdot 10$ & $5.97 \pm 0 \cdot 12$ & 0.681 \\
\hline$T a 1$ & 18 & $2 \cdot 00 \pm 0 \cdot 00$ & $9 \cdot 56 \pm 0.07$ & $1.63 \pm 0.07$ & $1 \cdot 23 \pm 0.09$ & $6 \cdot 70 \pm 0.09$ & 0.837 \\
\hline$S V$ & 46 & $2 \cdot 33 \pm 0 \cdot 15$ & $9.91 \pm 0.04$ & $1.33 \pm 0.05$ & $1 \cdot 31 \pm 0.05$ & $7 \cdot 27 \pm 0.06$ & 0.780 \\
\hline$L F$ & 21 & $2 \cdot 71 \pm 0 \cdot 10$ & $9 \cdot 29 \pm 0 \cdot 05$ & $0.91 \pm 0.06$ & $1 \cdot 16 \pm 0.07$ & $7 \cdot 21 \pm 0 \cdot 09$ & 0.454 \\
\hline$M H$ & 6 & $3 \cdot 00 \pm 0.00$ & $9.03 \pm 0.06$ & $0 \cdot 73 \pm 0 \cdot 13$ & $1 \cdot 62 \pm 0 \cdot 13$ & $6 \cdot 68 \pm 0 \cdot 15$ & 0.236 \\
\hline$C$ & 16 & $3 \cdot 00 \pm 0 \cdot 00$ & $9.04 \pm 0.06$ & $0.58 \pm 0.06$ & $1.96 \pm 0.12$ & $6 \cdot 54 \pm 0 \cdot 13$ & 0.489 \\
\hline
\end{tabular}

(1) $\bar{F}$ vs. $\bar{X} t . Y=10.65-0.53 X ; F(1,12)=51.94 ; P<0.01 . r=-0.9014 ; t(12)=7.21 ; P<0.001$

(2) $\bar{F}$ vs. $\bar{X} p . Y=3.90-1.02 X ; F(1,12)=55.88 ; P<0.01 . r=-0.9071 ; t(12)=7 \cdot 17 ; P<0.001$

(3) $\bar{F}$ vs. $\bar{X}$ i. $Y=0.64+0.32 X ; F(1,12)=25.84 ; P<0.01 . r=0.8257 ; t(12)=5.07 ; P<0.001$

(4) $\bar{F}$ vs. $\bar{X} d . Y=6 \cdot 13+0.17 X ; F(1,12)=1 \cdot 13 ; P>0.05 . r=0.2931 ; t(12)=1.06 ; 0.3<P<0.04$

(5) $\bar{F}$ vs. $S_{t}^{2} . Y=1.47-0.41 X ; F(1,12)=32.87 ; P<0.01 . r=0.8569 ; t(12)=5.76 ; P<0.001$

(6) $\bar{X} p$ vs. $\bar{X} i, Y=4 \cdot 71-2 \cdot 18 X ; F(1,12)=14.77 ; P<0.01 . r=-0.7430 ; t(12)=3 \cdot 85 ; P<0.01$

(7) $\bar{X} t$ vs. $\bar{X} p . Y=-13 \cdot 83+1.64 X ; F(1,12)=14 \cdot 31 ; P<0.01 . r=0.8493 ; t(12)=5 \cdot 57 ; P<0.001$

and interstitial chiasmata than correctly oriented ones (Bidau and Mirol, 1988). It is relevant to note however, that the same modifications occur in fusion homozygotes, where the restrictions imposed by chiasmata do not apply. Furthermore, non-fused telocentrics remain unaffected (see table 5).

It is interesting however, to note the following: while a pronounced reduction in chiasma frequency (especially of the proximal type) is expected in polymorphic populations due to the "need" of stabilising trivalent orientation, this restriction need not operate in populations where the fusions are fixed. Since only one population in which three fusions were fixed was obtained, a comparison was made between the former and a related population (SV) in which males homozygous for the same three fusions were considered. Although males from the monomorphic population had on average fewer total chiasmata than those from the polymorphic one, the former had more proximal chiasmata and the difference was statistically significant (table 8 ).

When considering these facts, one is confronted with two alternative hypotheses about the chiasmata modifications produced by the polymorphisms, as stated above. Colombo (1987), on the basis of his observations of a spontaneous fusion 5/7 heterozygote in L. argentina suggested that, since no redistribution of chiasmata occurred in chromosomes 5 and 7 in the mutant as compared with
Table 8 Comparisons of mean cell total $(\overline{\mathrm{X}} \mathrm{t})$ and proximal $(\overline{\mathrm{X}} \mathrm{p})$ chiasma frequencies between 16 males of the monomorphic $\mathrm{C}$ population (all homozygous for fusions $1 / 2,3 / 4$ and $5 / 6$ ) and 11 males from a polymorphic population (SV) also homozygous for the same three fusions

\begin{tabular}{llllll}
\hline Population & $\mathrm{n}$ & $\overline{\mathrm{X}} \mathrm{t}$ & $\mathrm{F}(1,268)$ & $\overline{\mathrm{X}} \mathrm{p}$ & $\mathrm{F}(1,268)$ \\
\hline $\mathrm{C}$ & 160 & 9.04 & $\begin{array}{l}32.17 \\
P<0.01\end{array}$ & 0.58 & $\begin{array}{l}52.47 \\
\text { SV }\end{array}$ \\
\hline
\end{tabular}

standard individuals, the modifications in the widespread polymorphic $3 / 6$ fusion are the result of a later adaptation to the polymorphic condition. This author also discusses the evidence provided by observations on other spontaneous fusions in Acrididae (Kayano and Nakamura, 1960; LópezFernández et al., 1984; Southern, 1967; Teoh and Yong, 1983) where no redistribution of chiasmata was reported. It is not safe however, to a priori accept this hypothesis solely on the tenuous grounds derived from observations on spontaneous mutants (a scanty amount indeed). In the first place, the studied fusion polymorphisms (very few in fact) are undoubtedly not a random sample of all fusions that occur spontaneously in nautre. This is certainly true of other rearrangements (i.e. inversions; Sperlich and Pfriem, 1986). Therefore, the successful extant polymorphisms may be simply those which originally survived owing to an instantaneous modification of the cross-over 

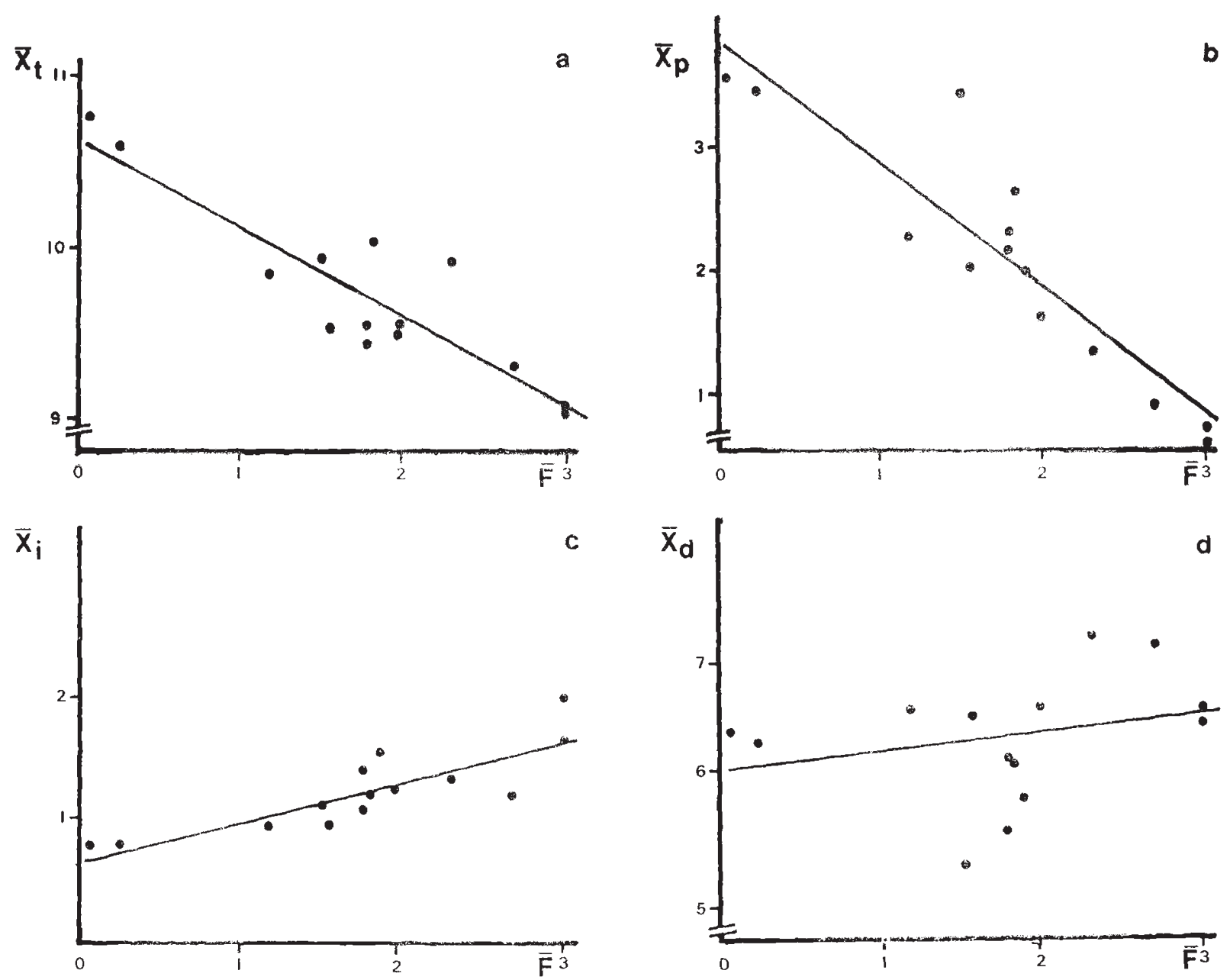

Figure 5 Relationship between mean number of different fusions per male $(\bar{F})$ and mean (a) total $\left(\bar{X}_{t}\right),(\mathrm{b})$ proximal $\left(\bar{X}_{p}\right),(\mathrm{c})$ interstital ( $\vec{i})$ and distal $(\bar{X} d)$ chiasmata per cell in 14 populations of $D$. pratensis. Regression equations and their significances are given in table?

pattern in heterozygous mutants. Extensive chiasma modifications certainly do occur in mutants heterozvgous for interchanges or fissions (Arana et al., 80; Hewitt, 1967; Parker, 1987; Parker et al. 19.2) and these are obviously a result of the rearrement itself. Second, comparisons have been metween different chromosomes which do not recessarily respond equally to the rearrangement. Ideally, comparisons should involve the same fusion, polymorphic in one population and sponxaneous in another.

Perhaps more relevant is the fact that it is difficult to envisaye a selective process by which proximal chiasmata are eiiminated in the fusion chromosomes without a concomitant elimination in the corresponding telocentrics of standards, unless genes responsible for chiasma control are tightly linked with the metacentric fusion chromosome. The latter is improbable since in D. pratensis all seven fusions behave equally: in all cases telocentrics have high proximal chiasma frequencies (see the results section) and besides, control of chiasma frequency is probably polygenic (Shaw, 1972).

It is then more plausible that the fusions exert some direct restricrions on proximal chiasma formation at the heterozygous and homozygous conditions through for example, modifications of synapsis. A possible model is the following: if chiasmata are formed preferentially in regions which include or are close to zones of pairing initiation which are paired eariy in prophase I and have the most protracted period of synapsis, the chance of chiasma formation in these regions may 

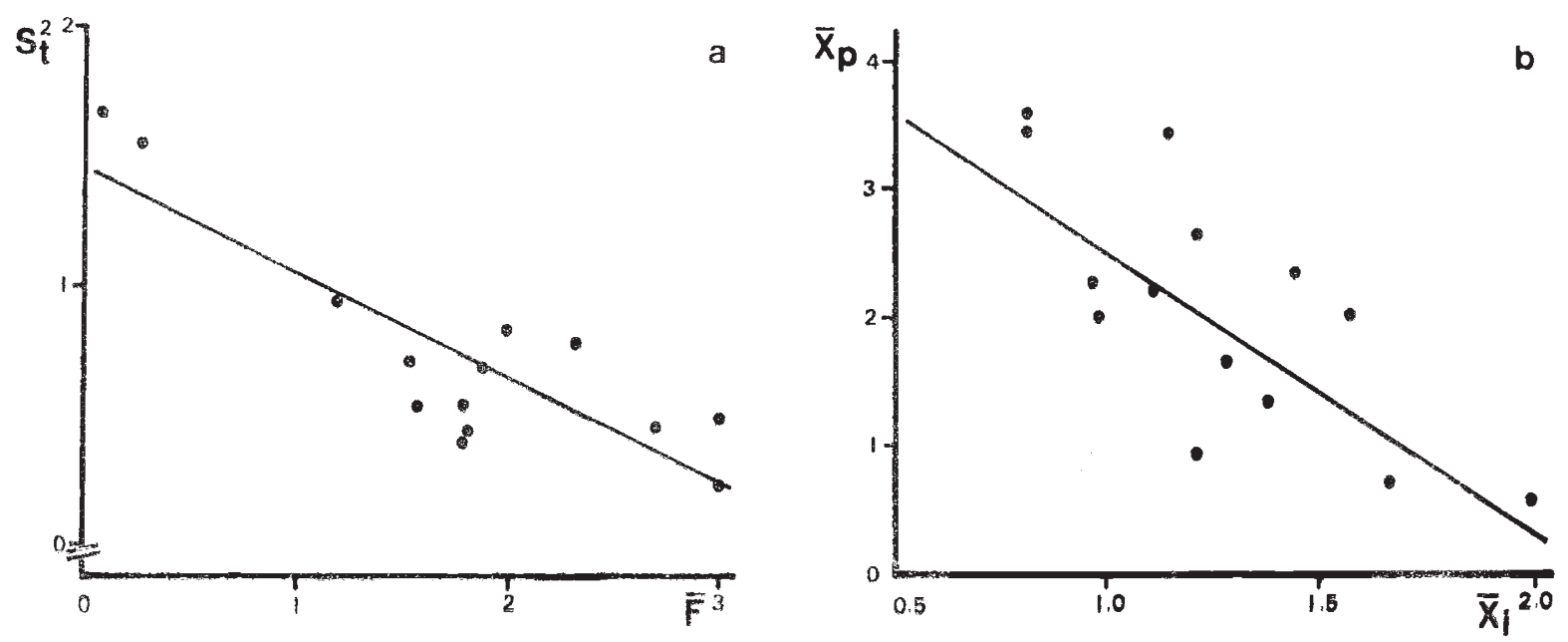

Figure 6 Relationship between (a) $F$ and mean between-cell variarce of cotal chiasmata $\left(S_{t}^{2}\right)$ in 14 populations of $D$. pratensts and (b) mean rrequency of intersticial $(\bar{X} i)$ and proximal $(\bar{X} p)$ chiasmata in the same populations. Regression equations and their significance are given in table 7 .

well be increased. Then, if unfused telocentrics have both ends attached to the nuclear memorane, they can initiate pairing from either or both ends, which could explain the $P / D$ chiasma distriburion. In fused chromosomes however, four original ends are replaced by two and the number of early pairing regions is consequentiy reduced and shifted ro distal ends only. This would explain both the reduction in toral chiasma frequency and the reduction in proximal chiasmata in fusion heterozygotes and nomozygotes.

Turning to the possible adaptive significance of the D. pratensis's polymorphisms one is tempted to relate their maintanence to the restrictions imposed upon recomivination. Fusions are not as effective suppressors of recombination as inversions but a fusion instantly reduces interchromosomal recombination by bringing together two formerly independent linkage groups, usually accompanied by a suppression of chiasmata in proximal portions of chromosomes as discussed above. These facts could allow the conservation of coadapted supergenes partially or completely protected from recombination. Thus the maintenance of the polymorphisms would become adaptive since fixation could, by eliminating the segregation restrictions of heterozygotes, result in an increase in crossing-over in regions previously protected (as in the C population described in Results) and the disruption of supergenes.

Two hypothese relate polymorphic rearrangements and supergenes, the postadaptation and the preadaptation hypotheses (Sperlich and Pfriem, 1986). In the first case, the newly arisen fusion couid be initially successful because of favourable position effects. The need for stabilising segregation in heterozygotes could then, by restricting chiasma formation, allow the surging of supergentes. That is, the decrease in recombination being a byproduct of the establishment of the polymorphism would not be the initial cause of its maintenance. In the second case one could envisage a situation in which some coadaptation already exists and any fusion that involves such gene arrangements should be favoured since it would protect them from recombination.

A model proposed for the chromosomal evolution of $D$. pratensis (Bidau, 1984, 1988) can be expanded when the effects of the fusions on recombination are considered. It proposes that range expansion of the species occurred mainly in the monomorphic standard form since these populations have more recombination potential and thus, a greater capacity for liberating genetic variability which allows the production of more gene arrangements to be selected for in order that the population becomes adapted to a new environment. Once a new colony adapts successfully to its new habitat, the fortuituous appearance of one or more fusions that include the adaptive gene combinations would generate the polymorphic condition to preserve them as explained above.

It is possible to relate this model to the centralmarginal model of evolutionary biology as it has been applied for example to Drosophila (Brussard, 1984; Sperlich and Pfriem, 1986). The model assumes that populations belonging or near to the centre of a species' range, have certain characteris- 
tics such as high density, high levels of genetic and phenotypic variation, etc. In contrast, peripheral populations are isolated, sparse, have low levels of chromosomal polymorphism, etc. A number of hypotheses concerning the inversion polymorphisms in Drosophila as related to this model have been put forward (Brussard, 1984).

When considering the distribution of fusion polymorphisms in $D$. pratensis it was shown that, at least in the sampled area, no clear pattern is evident (Bidau, 1988). Certainly, some fusions are widespread and others restricted to particular localities, and populations are generally very polymorphic. Exceptions however, do exist; two Patagonian populations have exceptionally high frequencies of standard individuals (PM and $G$ ) and are consequently the less polymorphic ones and those with the highest recombination indexes. Despite the wide ecological tolerance displayed by the species, these populations are the best candidates for being considered marginal (in the ecological sense) since environmental conditions in these areas are certainly more strenuous (see Bidau, 1984).

These populations, having more recombination potential, could liberate more genetic variability (if available) that would be of advantage in a new, unexploited environment. The PM and G populations would then agree with Carson's (1959) model in having low polymorphism and high recombination. It is however relevant to discuss some morphological data of $D$. pratensis (Bidau and Tosto, 1986). Although the putative marginal populations seem to be phenotypically more variable than those presumed to be central (or optimal in the ecological sense), no statistically significant correlation was found between degree of polymorphism and morphological variability. This is in contrast with the report of Westerman (1983) on Phaulacridium in which a negative correlation between recombination potential and phenotypic variability was demonstrated. He produced a very apt explanation: those populations with high crossover frequencies liberate much genetic variability which is subjected to selection very rapidly and consequently, rapidly lost. Populations with a lower recombination potential would preserve the extant genetic variability. In Westerman's (1983) case however, low recombination populations were the peripheral ones. A further case of a central-marginal distribution of a fusion polymorphism in a grasshopper was reported by Colombo (1988).

The case of $D$. pratensis is puzzling. On the one side, polymorphism is lower and recombina- tion higher in marginal populations; on the other, phenotypic variation shows no significant differences. The latter could be related to the fact that allozyme variability is not correlated with chromosomal variability (Brussard, 1984). It is relevant however to note that although central populations may be chromosomally more polymorphic, the type of polymorphism conditions the propositions of the central-marginal model: central populations may be highly polymorphic for $\mathrm{B}$ chromosomes which raise chiasma frequency, or inversions or fusions that decrease it. Hence, the chromosomal situation is possibly related not only to modifications of recombination but to other effects due to the rearrangements themselves.

The hypothesis that the PM and G populations are recent invaders is appealing but by no means definitive.

Acknowledgements I am fully indebted to Dr Cristina D'Aiutolo and my sons, Claudio Jr and Pablo, for help in the collection and processing of the grasshoppers. I am also indebted to my collaborators, Miss Daniela Tosto and Miss Patricia Mirol for their patient work, useful comments and good company. Thanks are also due to my colleague and friend $\mathrm{Dr}$ Pablo Colombo for the critical review of the manuscript and many stimulating discussions. I also wish to thank an anonymous reviewer whose corrections and suggestions improved the manuscript substantially.

This work was supported by grants from CONICET and Universidad de Buenos Aires.

\section{REFERENCES}

ARANA, P., SANTOS, J. L. AND GiRAldez, R. 1980. Chiasma interference and centromere co-orientation in a spontaneous translocation heterozygote of Euchorthippus pulvinatus gallicus (Acrididae: Orthoptera). Chromosoma, 78 , $327-340$.

BIDAU, C. J. 1984. Ph.D. Thesis, Universidad de Buenos Aires. BIDAU, C. J. 1986. Geographic distribution of chromosome polymorphisms in Dichroplus pratensis Bruner (Melanoplinae, Acrididae) in Argentina. Proc. IV Triennial Meet., Pan Amer. Acridol. Soc., Saskatoon, 165-166.

BIDAU, C. J. 1988. Zonas híbridas en ortópteros: el ejemplo de Dichroplus pratensis (Acrididae). Revista Soc. Entomol. Argentina (In press).

BIDAU, C. J. AND HASSON, E. R. 1984. Population cytology of Leptysma argentina Bruner (Leptysminae, Acrididae). Genetica, 62, 161-175.

BIDAU, C. J. AND MIROL, P. 1988. Orientation and segregation of Robertsonian trivalents in Dichroplus pratensis (Acrididae). Genome, 30, 947-955.

BIDAU, C. J. AND TOSTO, D. 1986. Análisis de la variabilidad morfológica de razas cromosómicas de Dichroplus pratensis en relación a la capacidad potencial de recombinación. XVII Congr. Arg. Genet., Río Cuarto, 65.

BRUSSARD, P. F. 1984. Geographic patterns and environmental gradients: the central marginal model in Drosophila revisited. Ann. Rev. Ecol. Syst., 15, 25-64. 
CARSON, H. L. 1959. Genetic conditions that promote or retard the formation of species. Cold Spring Harbor Symp. Quant. Biol., 24, 87-103.

COLOMBO, P. C. 1987. Effects of centric fusions on chiasma frequency and position in Leptysma argentina. 1. Spontaneous and stable polymorphic centric fusions. Genetica, $72,171-179$.

COlOMBO, P. C. 1988. Polimorfismos cromosómicos en Orthoptera. Revista Soc. Entomol. Argentina (In press).

CONFALONIERI, V. A. 1988. Effects of chromosome polymorphisms on chiasma conditions in Trimerotropis pallidipennis (Oedipodinae: Acrididae), Genetica 76, 171-179.

CONFALONIERI, v. A. AND COLOMBO, P. C. 1989. Inversion polymorphism in Trimerotropis pallidipennis (Orthoptera): clinal variation along an altitudinal gradient. Heredity, 62, $107-112$

GOÑI, B., DE VAIO, E. S., BELTRAMI, M., LEIRA, M. S., CRIVEL, M., PANZERA, F., CASTEllanOS, P. AND BASSO, A. 1985. Geographic patterns of chromosomal variation in populations of the grasshopper Trimerotropis pallidipennis from Southern Argentina. Can. J. Genet. Cytol., 27, 259-271.

HEWITT, G. M. 1967. An interchange which raises chiasma frequency. Chromosoma, 21, 285-295.

HEWITT, G. M. 1979. Orthoptera. Grasshoppers and crickets. In Animal cytogenetics. 3. Insecta 1. (B. John, ed.). Gebruder Borntraeger, Berlin-Stuttgart.

HEWITT, G. M. AND SCHROETER, G. L. 1968. Population cytology of Oedaleonotus. 1. The karyotypic facies of Oedaleonotus enigma (Scudder). Chromosoma, 25, 121140.

JOHN, B. The role of chromosome change in the evolution of Orthopteroid insects. In Sharma, A. K. and A. S. (Eds) Chromosomes in the Evolution of Eukaryotes. Vol. 1, CRC Press, Boca Raton, pp. 1-110.

JONES, R. N. AND REES, H. 1982. B chromosomes. Academic Press, London-New York.

KAYANO, H. AND NAKAMURA, K. 1960. Chiasma studies in structural hybrids. V. Heterozygotes for a centric fusion and a translocation in Acrida lata. Cytologia, 25, 476-480.

LIEBERMANN, J. 1963. Contribución al conocimiento de Dichroplus pratensis (Orth., Acrid.) IDIA, 191, 23-28.

LOPEZ-FERNANDEZ, C., RUFAS, J. S., GARCIA DE LA VEGA, C. AND GOSAlveZ, J. 1984. Cytogenetic studies on Chorthippus jucundus (Fisch.) (Orthoptera). III. The meiotic consequences of a spontaneous centric fusion. Genetica, $63,3-7$.
PARKER, J. S. 1987. Increased chiasma frequency as a result of chromosome rearrangement. Heredity, 58, 87-94.

PARKER, J. S., PALMER, R. W., WHITEHORN, M. A. F. AND EDGAR, L. A. 1982. Chiasma frequency effects of structural chromosome change. Chromosoma, 85, 673-686.

RIVA, E., FOX, D. P., GIRALDEZ, R. AND SANTOS, J. L. 1984. Chiasma frequency and distribution in the presence and absence of supernumerary chromosome segments in the grasshopper, Euchorthippus pulvinatus gallicus. Heredity, 53, 101-106.

SHAW, D. D. 1972. Genetic and environmental components of chiasma control. II. The response to selection in Schistocerca. Chromosoma, 37, 297-308.

SMITH, S. G. 1966. Natural hybridization in the coccinellid genus Chilocorus. Chromosoma, 18, 380-406.

SMITH, S. G. AND VIRKKI, N. 1978. Coleoptera. In John, B. (Ed) Animal Cytogenetics 3. Insecta 5. Gebruder Borntraeger, Berlin-Stuttgart.

SOUTHERN, D. I. 1967. Spontaneous chromosome mutations in Truxaline grasshoppers. Chromosoma, 22, 241-257.

SPERLICH, D. AND PFRIEM, P. 1986. Chromosomal polymorphisms in natural and experimental populations. In The Genetics and Biology of Drosophila, vol. 3e, chapter 37, Academic Press, London, pp. 257-309.

TEOH, S. B. AND YONG, M. S. 1983. A spontaneous fusion heterozygote in the tropical grasshopper, Valanga nigricornis (Burmeister). Caryologia, 36, 165-173.

TOSTO, D., MIROL, P. AND BIDAU, C. J. 1987. Aspectos de las relaciones entre las fusiones céntricas y la distribución de los quiasmas en Dichroplus pratensis (Melanoplinae, Acrididae). XVIII Congr. Arg. Genet., Buenos Aires, 21.

WEISSMAN, D. B. 1976. Geographical variability in the pericentric inversion system of the grasshopper Trimerotropis pseudofasciata. Chromosoma, 55, 325-347.

WESTERMAN, M. 1983. Chiasma frequency and variability of morphological characters in populations of two grasshopper species. Heredity, 51, 501-506.

WHITE, M. J. D. 1973. Animal cytology and evolution. 3rd Edit. Cambridge Univ. Press, London-New York.

WHITE, M. J. D. AND MORLEY, F. H. W. 1955. Effects of pericentric rearrangements on recombination in grasshopper chromosomes. Genetics, 40, 604-619. 